\title{
Development of the environmental policy priorities index for Japan 2010 (JEPIX 2010)
}

\author{
S. Kumagai \\ Department of Industrial and Systems Engineering, \\ Aoyama Gakuin University, Japan
}

\begin{abstract}
Some advanced companies in Japan introduce LCIA (Life Cycle Impact Assessment) method such as EcoIndicator, EcoScarcity and LIME. Environmental Policy Priorities Index for Japan (JEPIX 2003) was developed based on the Swiss EcoScarcity method. It is an integrative technique that converts emission data of multiple environmental load substances to a singlescore indicator. It assesses the distance to target of each substance emission. JEPIX 2010 has been developed using the most resent Japanese inventory data and legislation target. In JEPIX 2010, there are diversified identified categories of environmental aspect, including GHG, ODS, SOX, NOX, particles/dust, dioxins, VOC, total Nitrogen, total Phosphorous, COD, BOD, waste material. Comparison of the two sets of EcoFactors (JEPIX 2003 and JEPIX 2010) and Japanese national ecobalances, which are obtained from the EcoFactors, show the change of priority of Japanese environmental policy.

Keywords: JEPIX, environmental performance, Ecofactor, Ecoscarcity.
\end{abstract}

\section{Introduction}

Japanese environmental accounting guideline by the Ministry of Environment recommends the calculation of single-score environmental indicator. It is useful not only for environmental management within the company but also for effective communication with the outside stakeholders by environmental reporting. Some advanced companies in Japan introduce LCIA (Life Cycle Impact Assessment) method such as EcoIndicator, EcoScarcity and LIME [1, 2]. Environmental Policy Priorities Index for Japan (JEPIX) 2003 [7, 8] was developed based on the Swiss EcoScarcity (BRUWAL SR133/SR297) method 
[3]. It has been used in environmental reports of several advanced companies as a single score performance indicator [9].

\section{Environmental policy priorities index for Japan}

\subsection{Ecoscarcity method}

The environmental policy priorities index evaluates the environmental performance of enterprises. It is an integrative technique that converts emission data of multiple substances to a single-score indicator. It assesses the distance to target of each substance emission - the environmental policy versus actual environmental situation based on the mass flow data. The amount of difference between actual national flows of environmentally harmful substance and national environmental regulations target value (e.g. $\mathrm{CO}_{2}$ reduction target in Kyoto Protocol) is regarded as weighting factor of the substance, called EcoFactor.

This index, generally known as an integration method, converts the data on emissions of several environmental load substances into a single environmental load as shown in (1).

$$
\sum_{i \in\{\text { Environmental Load Substances }\}} F_{i} \times E_{i}
$$

\section{Fi: EcoFacor of Substance Mi, Ei : Emission of Mi}

In order to convert the emissions of several environmental load substances into a single environmental load, the environmental load for unit emissions of environmental load substances is defined as a weighting factor, called EcoFactor. Because the weighting factor is based on emissions data, it enables extraction of objective and quantitative environmental performance data.

JEPIX evaluates the distance to the target, viz. the gap between the target emissions and the actual emissions based on the environmental policy on environmental load substances, according to the flow data of the materials, in light of the concept of the EcoScarcity method developed in Switzerland, and determines the environmental load per unit emissions as a weighting factor.

\subsection{Definitional equation for EcoFactor}

The EcoFactor is defined as eqn (2). It calculates the relative weight of an environmental load substance by evaluating the relative distance of actual emissions from the policy target, $F_{k}$. It is expressed by the unit of EIP (Environmental Impact Point).

$$
\text { EcoFactor }=\frac{1}{F_{k}} \times \frac{F}{F_{k}} \times c
$$

F: Actual Emission of Substance (Actual Flow)

F: Emission of the Policy Target (Target Flow) , C: Constant $1 \times 10^{12}$ 
It should be noted that the actual flow $F$ and the target flow $F_{k}$ are not the data of concentration $\left(\mathrm{kg} / \mathrm{m}^{3}\right)$ but are the total emissions $(\mathrm{kg})$ of an environmental load substance. An environmental standard is established for environmental load substances mostly as a regulation of emission concentration. The EcoFactor of JEPIX is calculated by defining the target total emissions, which is established as a policy target, as the target flow $F_{k}$ and defining the underlying actual emissions as the actual flow $F$.

Some substances are controlled in environmental standards only for observed concentration values or concentrations. For such substances, EcoFactors will be obtained by estimating emissions from the concentrations.

\subsection{Base year and target year}

The policy target for the reduction of environmental load substances is based on the base year, when the target is established, and the target year, when the target should be achieved. For example, the Kyoto Protocol, which sets GHG (greenhouse gas) reduction targets, was established in the base year of 1990 with the aim of achieving its target of reducing the base year emissions by $6 \%$ by the target year of 2012. The base year and the target year of policy targets vary according to the environmental load substances concerned.

\section{JEPIX 2010}

\subsection{Environmental aspects to be converted in JEPIX}

The environmental aspects targeted for EcoFactor calculation and the law regulations, which serve as the basis for the target flow, are as shown in Table 1.

Table 1: Environment aspects and relevant legislation.

\begin{tabular}{|c|c|c|}
\hline Environmental Aspects & JEPIX2003 & JEPIX2010 \\
\hline $\begin{array}{c}\text { Global Warming by Green } \\
\text { House Gasses (GHG) }\end{array}$ & Kyoto Protocol & $\begin{array}{l}\text { Kyoto Protocol Target } \\
\text { Achievement Plan (28 } \\
\text { March 2008) }\end{array}$ \\
\hline $\begin{array}{l}\text { Ozone Depletion by } \\
\text { Ozone Depleting } \\
\text { Substances (ODS) }\end{array}$ & $\begin{array}{l}\text { CFC Management } \\
\text { Strategy of Japan、Act } \\
\text { on Ensuring the } \\
\text { Implementation of } \\
\text { Recovery and } \\
\text { Destruction of } \\
\text { Fluorocarbons } \\
\text { concerning Designated } \\
\text { Products (Montreal } \\
\text { Protocol on Substances } \\
\text { that Deplete the Ozone } \\
\text { Layer) }\end{array}$ & $\begin{array}{c}+ \\
\text { (Legislation to automobile } \\
\text { recycling、Act for } \\
\text { Recycling of Specified } \\
\text { Kinds of Home } \\
\text { Appliances) }\end{array}$ \\
\hline
\end{tabular}


Table 1: $\quad$ Continued.

\begin{tabular}{|c|c|c|}
\hline \multirow{2}{*}{$\begin{array}{l}\text { Hazardous chemical } \\
\text { Substances, including } \\
\text { Dioxins }\end{array}$} & $\begin{array}{c}\text { Act on Special Measures } \\
\text { concerning } \\
\text { Countermeasures against } \\
\text { Dioxins }\end{array}$ & $\begin{array}{l}\text { Reduction Plan of Dioxins } \\
\text { emissions in the course of } \\
\text { business activities Dioxins }\end{array}$ \\
\hline & $\begin{array}{c}\text { Voluntary Management } \\
\text { Plan for Hazardous air } \\
\text { Pollutant by Japanese } \\
\text { METI (2002) }\end{array}$ & $\begin{array}{l}\text { VOC Emission Control } \\
\text { (H18.4 April 2006) }\end{array}$ \\
\hline $\begin{array}{c}\text { Air Pollution by } \\
\text { Photochemical Oxidants }\end{array}$ & Environmental Standard & $\begin{array}{l}\text { VOC Emission Control } \\
\text { (H18.4 April 2006) }\end{array}$ \\
\hline Air Pollution by SPM & Environmental Standard & $\begin{array}{l}\text { VOC Emission Control } \\
\text { (H18.4 April 2006) }\end{array}$ \\
\hline Air Pollution by $\mathrm{NO}_{\mathrm{X}}$ & $\begin{array}{l}\text { Automobile } \mathrm{NO}_{\mathrm{X}} \mathrm{PM} \\
\text { Control law }\end{array}$ & $\leftarrow$ \\
\hline $\begin{array}{l}\text { Water Quality for River by } \\
\text { BOD }\end{array}$ & Environmental standard & $\leftarrow$ \\
\hline $\begin{array}{l}\text { Water Quality for Closed } \\
\text { Sea lakes by COD }\end{array}$ & $\begin{array}{l}\text { Water Quality Pollution } \\
\text { Control Act, The } 5^{\text {th }} \\
\text { Total Emission } \\
\text { Reduction Ac }\end{array}$ & $\begin{array}{l}\text { Water Quality Pollution } \\
\text { Control Act, The } 6^{\text {th }} \text { Total } \\
\text { Emission Reduction Ac }\end{array}$ \\
\hline $\begin{array}{l}\text { Water Quality for Closed } \\
\text { Sea and lakes by } \mathrm{N} \text { and } \mathrm{P}\end{array}$ & $\begin{array}{l}\text { Water Quality Pollution } \\
\text { Control Act, The } 5^{\text {th }} \\
\text { Total Emission } \\
\text { Reduction Act }\end{array}$ & $\begin{array}{l}\text { Water Quality Pollution } \\
\text { Control Act, The } 6^{\text {th }} \text { Total } \\
\text { Emission Reduction Act }\end{array}$ \\
\hline $\begin{array}{l}\text { Waste Management by } \\
\text { Landfill Capacity }\end{array}$ & $\begin{array}{l}\text { The } 1^{\text {st }} \text { Basic Act on } \\
\text { Establishing a Sound } \\
\text { Material-Cycle Society }\end{array}$ & $\begin{array}{l}\text { Fundamental Plan for } \\
\text { Establishing a Sound } \\
\text { Material-Cycle Society } \\
\text { (March 2008) }\end{array}$ \\
\hline $\begin{array}{c}\text { Noise Pollution by Road } \\
\text { Traffic Noise }\end{array}$ & Environmental standard & N.A \\
\hline
\end{tabular}

\subsection{Summary of EcoFactor}

The calculated EcoFactors are outlined in Table 2.The national ecobalance in Japan will be obtained by summarizing the actual flows and target flows of the total emissions of environmental load substances in all over Japan by environmental aspects, and multiplying the summarized flows by the EcoFactors for the respective aspects. The national ecobalance graph outlines the variety of priorities in the policy issues of Japan. The priorities between JEPIX2003 (Figure1) [7] and JEPIX2010 (Figure 2) cannot be compared simply because the environmental aspects of JEPIX2003 are categorized differently from those in JEPIX2003. However, it is a notable difference that the importance of GHG is relatively lower in JEPIX2010 than in JEPIX2003. 
Table 2: $\quad$ Ecofactors in JEPIX.

\begin{tabular}{|c|c|c|c|}
\hline & $\begin{array}{c}\text { JEPIX2010 } \\
(\mathrm{EIP} / \mathrm{kg})\end{array}$ & $\begin{array}{c}\text { JEPIX2003 } \\
(\mathrm{EIP} / \mathrm{kg})\end{array}$ & JEPIX2010/JEPIX2003(\%) \\
\hline $\mathrm{CO}_{2}$ & 0.779 & 0.985 & 79 \\
\hline $\mathrm{ODS}$ & 672,925 & 429,282 & 157 \\
\hline $\mathrm{COD}$ & 4,010 & 3,272 & 123 \\
\hline $\mathrm{N}$ & 9,319 & 7,973 & 117 \\
\hline $\mathrm{P}$ & 523,054 & 84,429 & 620 \\
\hline Waste & 50.1 & 58.7 & 85 \\
\hline SPM & 8690 & 4899 & 817 \\
\hline Dioxins & 1776 & 258 & - \\
\hline VOC & 882 & - & \\
\hline
\end{tabular}

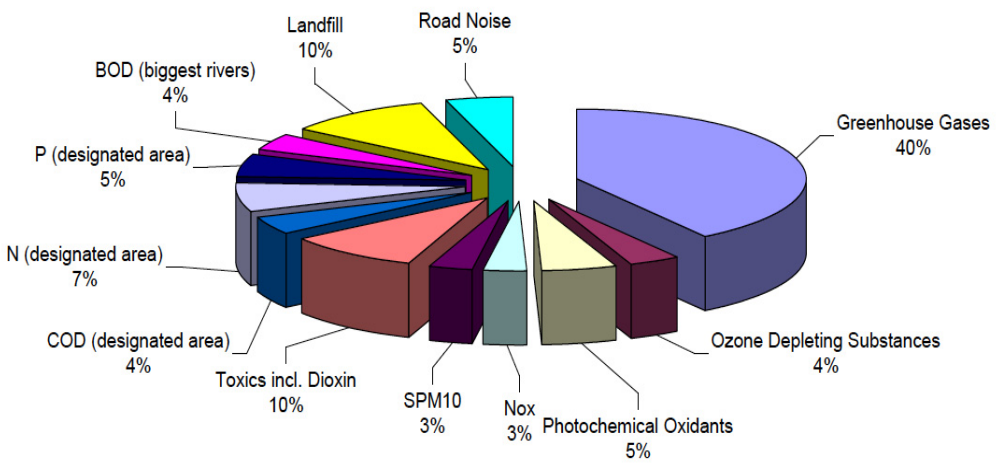

Figure 1: Japanese national ecobalance in JEPIX2003.

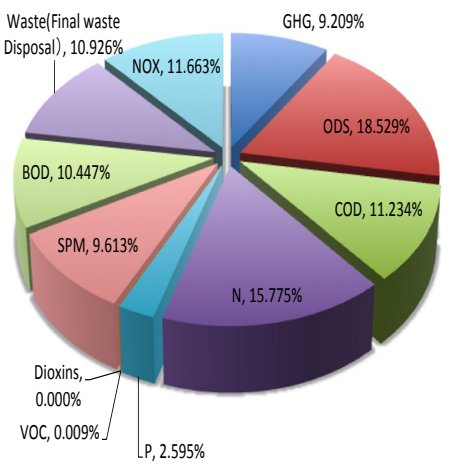

Figure 2: Japanese national ecobalance in JEPIX2010. 
EcoFactor is responsive to change of the distance to target. For example, Figure 3 shows the changes in EcoFactors resulting from the change of the present GHG flow from the 2004 level to the 2009 level. A sharp decline is seen in the EcoFactor since 2008. It is considered to be significantly attributable to the economic slump.

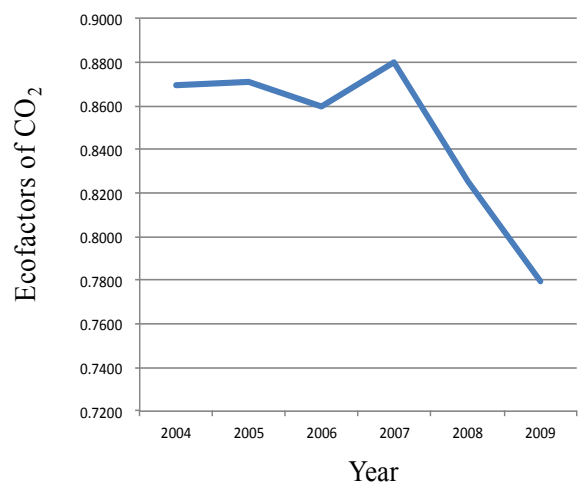

Figure 3: $\quad \mathrm{CO}_{2}$ EcoFactors.

\section{Calculation process for JEPIX2010 Ecofactors}

\subsection{GHG: greenhouse gas}

Greenhouse gases (GHG) consist of various substances such as $\mathrm{CO}_{2}$, methane, dinitrogen oxide $\left(\mathrm{N}_{2} \mathrm{O}\right)$, and three fluorinated gases including HFC (HFC, PFC, SF6) of energy origin and non-energy origin.

The data on actual GHG flow is available from the Greenhouse Gas Inventory [10]. The actual flow of GHG in 2009 is $1.209 \times 10^{12} \mathrm{~kg}-\mathrm{CO}_{2}$

The target flow is based on the Kyoto Protocol similarly as in the JEPIX2003. The progress management method for the Kyoto Protocol was approved at the cabinet meeting on March 28, 2008 as the "Kyoto Protocol Target Achievement Plan (revised edition)." Later, the greenhouse gas reduction target was set out on July 17, 2009 based on the final data for fiscal year 2007 as the "Progress of the Kyoto Protocol Target Achievement Plan" [11].

The final data for fiscal year 2007 shows that the total greenhouse gases emissions in Japan was approximately 1,374 million tons in carbon dioxide equivalent, a 9.0\% increase compared with the base year level. Specific reduction targets are newly set for the energy emissions of industrial, commercial and other, household and energy conversion sectors.

For three gases including alternatives for fluorocarbon (percentage of total emission: 4\%), although there are several increase factors of emissions such as the increase in HFC emissions due to the progress in substitution from ozonedepleting substances, it is necessary to control the increase amount to $+28.7 \%$. 
Further, in terms of forest sink measures, it is necessary to ensure forest absorption of greenhouse gases by $3.8 \%$ compared with the base year level by continuously promoting reforestation. As a result, the target flow of GHG is $1.2455 \times 10^{12} \mathrm{~kg}^{-\mathrm{CO}_{2}}$

The Kyoto Protocol Target Achievement Plan sets target values for HFC, PFC, and SF6. Those target values take into consideration the increase in the emissions of substitute chlorofluorocarbon resulting from the progress in substitution from chlorofluorocarbons that are ozone-depleting substances.

\subsection{Ozone-depleting substances (ODS)}

In light of the Vienna Convention (1985) and the Montreal Protocol (1987), the Ozone Layer Protection Law was established in 1987. In 2001, the CFC Management Strategy of Japan was announced that shows a road map to reduce the production, use, and atmospheric emission of ODS.

The actual flow of ozone-depleting substances is published [12]. The total ODS emissions are converted to CFC-11 (trichlorofluoromethane) equivalent emissions using the ozone depletion potential (ODP). As a result, the actual flow becomes 3,899,300 ODP-kg.

No target emissions are specifically set for ODS. Environmental emissions from heat insulators in use, refrigerators in operation, and so on are estimated [13]. Those emissions may be regarded as stock amount. Those emissions will be regarded as acceptable target flow because no regulations have been established for the recovery or destruction. The target emission total is $2,407,187$ ODP-kg.

\subsection{Hazardous chemical substances containing dioxin}

Dioxin emissions are published in the dioxins emissions inventory [32]. According to the data, the total dioxins emissions are on a downward trend year by year. In 2008, the total dioxin emissions decreased by approximately $43 \%$ from 2003 level (by approximately 97\% from the 1997 level) at $215 \mathrm{~g}$ to $223 \mathrm{~g}$ $\mathrm{TEQ} /$ year.

In the "Government Plan to Reduce Dioxin Levels Resulting from Business Activities," which was formulated based on the Law Concerning Special Measures against Dioxins, the target reduction level for 2010 is set at $315 \mathrm{~g}$ to $343 \mathrm{~g}$ TEQ/year (reduction by approximately 15\% from the 2003 level).

\subsection{VOC: Volatile organic compounds}

Volatile organic compounds (VOCs) are a causative agent for photochemical oxidant and SPM (suspended particulate matters) and are contained in printing inks, adhesives, paints, and so on. Approximately 200 substances are classified into VOCs such as toluene, xylene, dichloromethane, and acetic ester.

The 2004 revised Air Pollution Control Law was promulgated with the objective of preventing air pollution with photochemical oxidant and SPM. The VOC emission control started on April 1, 2006 with an aim of reducing the emissions from fixed emissions sources such as factories by $30 \%$ by 2010 . 
The emissions inventory on volatile organic compounds is published [33]. The following tables summarize the actual flow (2008) and the target flow $(30 \%$ reduction from the 2000 level) for the respective substances.

EcoFactors can be also calculated by the respective VOC substances. In this case, the EcoFactors vary significantly because the absolute values of target flows differ greatly among the substances. For example, while the EcoFactor for n-propyl acetate is $314,938,775,510(\mathrm{EIP} / \mathrm{kg})$, the EcoFactor for toluene is 4,254 EIP/kg. Scale-adjusted EcoFactors can be calculated. Those EcoFactors were calculated with constant $\mathrm{C}$ that was adjusted so that the average of EcoFactors of all the substances may become $882 \mathrm{EIP} / \mathrm{kg}$.

\subsection{Air pollution by SPM: suspended particulate matter}

SPMs are particulate matters of $10 \mu \mathrm{m}$ or less in diameter that are suspended in air for relatively long periods of time. They are absorbed by the respiratory system and cause health hazards. SPMs are continuously monitored based on the Air Pollution Control Law by 1961 monitoring stations located all over Japan in prefectures and designated cities under the Air Pollution Control Law.

The environmental quality standard of SPM concentration in Japan is defined as $0.10 \mathrm{mg} / \mathrm{m}^{3}$ or lower in daily average of hourly value, and $0.20 \mathrm{mg} / \mathrm{m}^{3}$ or lower in hourly value. The environmental quality standard achievement rate [31] was $98.8 \%$ for general environmental air monitoring stations and $99.5 \%$ for roadside air pollution monitoring stations, thus remained almost the same as the year 2008 level (general environmental air monitoring stations: 99.6\%, roadside air pollution monitoring stations: $99.3 \%$ ) for both monitoring stations.

The emission of SPM is assumed to be $55 \%$ of PM emission [35]. Since the PM emission in 2000 is $2.15 \times 10^{8}$ [36], the actual flow of SPM is estimated to be $118,250,000 \mathrm{~kg}$.

In order to obtain target flow of SPM, reduction rate is calculated by the formula below, using concentration data [37] of monitoring stations.

SPM Reduction Rate $=$

SPM A.C of Monitoring stations - SPM A.C of the Prefectures satisfying E.S

SPM A.C of Monitoring stations

\section{A.C: Average Concentration, E.S: Environmental Standard}

\subsection{Air pollution by Nitrogen Oxide（NOX）}

National total emission of NOX in 2005 is $1,920,000,000 \mathrm{~kg}$ [14]. The sources of nitrogen oxides (NOX) are divided into the mobile sources such as automobiles and the stationary sources such as incinerators.

(1) Stationary source In eight prefectures (Tokyo Metropolis, Osaka, Kanagawa, Saitama, Mie, Hyogo Prefecture, Aichi, Chiba), emission targets for stationary sources [15] are specified. The actual emissions in 2005 were obtained 
from the Summary Result of the General Survey of the Emissions of Air Pollutants [16].

For the other prefectures with no target values specified, target values were calculated by multiplying the actual emissions [15] by the value of target emissions/actual emissions of the eight prefectures with target values specified. The value of target emissions/actual emissions applied to the above calculation was selected from among those of eight prefectures by selecting an appropriate value according to the order of precedence of total emissions arranged in ascending order. As a result, target emission is $393,820,979 \mathrm{~kg}$

(2) Mobile source In eight prefectures where mobile sources are concentrated (Tokyo Metropolis, Osaka Prefecture, Kanagawa Prefecture, Saitama Prefecture, Mie Prefecture, Hyogo Prefecture, Aichi Prefecture, Chiba Prefecture), emissions targets for mobile sources are specified based on the Law Concerning Special Measures for Total Emission Reduction of Nitrogen Oxides from Automobiles in Specified Areas.

Data on emissions from mobile sources by prefectures are not available for prefectures other than the eight prefectures as of August 2011. Accordingly they were estimated by regression formula.

Emissions from mobile sources in prefectures other than the eight prefectures were estimated by regression formula according to the NOX Emission Rates By Vehicle Types based on the total vehicle ownership by prefectures [17] and the NOX emissions by fuel types and vehicle types [18]. As a result, target emission is $1,167,817,566 \mathrm{~kg}$

\subsection{River water quality based on the biochemical oxygen demand (BOD)}

Biochemical oxygen demand is used as a water quality index for rivers. The BOD does not refer to a specific substance but represents the amount of aquatic organisms and so on as the amount of oxygen required for aquatic microorganisms to oxidatively decompose them.

The Measurement Results of Water Quality in Public Waters [19] shows that the environmental quality standard achievement rate of BOD in rivers remains almost the same at $92.3 \%$ (the same point as in the preceding fiscal year).

BOD emissions are obtained by combining the emissions from pollution sources (domestic wastewater, commercial wastewater, industrial wastewater, livestock wastewater).

(1) BOD emissions from domestic wastewater

The BOD emissions from domestic wastewater is obtained by multiplying the daily per-capita unit of pollution loading, 58g/man/day [20] by the total population. The BOD removal rate will vary among domestic wastewater treatment facilities [21]. The total BOD emissions of domestic wastewater from households through the respective domestic wastewater treatment facilities was calculated based on the penetration rates of the respective facilities.

From the above procedures, the BOD emissions of domestic wastewater were calculated as $259,752,980 \mathrm{~kg} /$ year $\left(2.68 \times 10^{6}\right.$ (ton/year) [25]). 
(2) BOD emissions from commercial wastewater

The amount of commercial wastewater in FY 2005 was 1,355,000,000 $\mathrm{m}^{3} /$ year [21]. Given the water quality of commercial wastewater treated as the water quality of domestic wastewater, the BOD emissions from commercial wastewater is obtained by multiplying the amount of commercial wastewater by the BOD concentration in wastewater, $200 \mathrm{mg} / \mathrm{l}$. Thus the BOD emissions become $271,000,000 \mathrm{~kg} /$ year $\left(2.68 \times 10^{6}\right.$ (ton/year) [25]).

(3) BOD emissions from industrial wastewater

For the BOD emissions from industrial wastewater, the BOD wastewater quality is published for representative specified facilities [21]. It is described along with the BOD emissions per shipment amount by industrial classifications. The BOD emissions were calculated by multiplying it by the total shipment amount.

As a result, the BOD emissions from industrial wastewater were calculated as $4,403,318,092 \mathrm{~kg} /$ year $\left(6.28 \times 10^{6}\right.$ (ton/year) [25]).

\section{(4) BOD emissions from livestock wastewater}

BOD emissions from livestock wastewater are virtually the emissions from urine sewage. They are obtained by multiplying the unit emissions from milking cows and the unit emissions from finishing pigs [23] by the respective numbers of reared animals [24].

In order to obtain a target flow, the ratio of the estimated emissions $\mathrm{F}$ on the contaminating side (emitter side) against the estimated emissions $F^{\text {observed }}(1 / \mathrm{X})$ will be considered. In other words, the two estimated emissions will be assumed to be in a linear relationship. The $F^{\text {observed }}$ on the observed side corresponding to the actual flow $F=4,934,778,872 \mathrm{~kg}$ is a value calculated by multiplying the BOD concentration measured at rivers by the river water volume. A linear relationship will be assumed to be formed between the target flow on the observed side and the target flow on the output side too.

The estimated BOD emissions on the observed side, $F^{\text {observed }}$, is a sum of the emissions obtained by multiplying river water amount by the average BOD concentration $(\mathrm{mg} / \mathrm{l})$ [24]. Thus, $F^{\text {observed }}=155,104,641 \mathrm{~kg}$ is obtained. Accordingly, the quotient of the estimated BOD emissions on the emitter side divided by the estimated BOD emissions on the observed side becomes $4,934,778,872 \mathrm{~kg} / 155,104,641 \mathrm{~kg}=31.8$.

On the other hand, the target flow on the observed side is obtained by summing up the product of the river water amount multiplied by an environmental quality standard value of the type concerned $(\mathrm{mg} / \mathrm{l})$. Thus the sum becomes $140,834,670 \mathrm{~kg}$. Then, the target flow $F_{k}=4,478,489,400 \mathrm{~kg}$ was obtained

BOD Target flow of Pollution Source $=$

Target Flow of Observed Pollution $\times \frac{\text { BOD Emission from the Source (Estimated) }}{B O D \text { Observed Pollution(Estimated) }}$ 


\subsection{Water quality in closed sea areas in terms of chemical oxygen demand (COD)}

COD is the amount of oxygen required to oxidize oxidizable substances in water and is used to assess the water quality in lakes and closed sea areas. The Measurement Results of Water Quality in Public Waters for FY 2009 shows that the environmental quality standard achievement rate of COD increased by $50 \%$ (decrease by $3.0 \%$ from the preceding fiscal year) in lakes and marshes and by $79.2 \%$ (increase by $2.8 \%$ from the preceding fiscal year) in sea areas. [20]. Thus while the achievement rate remains low in lakes and marshes, it remained at a similar level as in the preceding fiscal year in sea areas.

The actual flow of COD is a sum of the COD emissions to the designated enclosed water areas (Tokyo Bay, Ise Bay, and Seto Inland Sea) and the COD emissions to lakes and marshes. While the annual total emissions are published for the former [26], the COD emissions for the latter will be estimated by multiplying the COD concentration in lakes and marshes, where the environmental quality standard of COD is not satisfied, by the volume of the lakes and marshes.

\section{COD Actual Flow =}

Total COD Emission of the Designated Closed Seas in B.E

$+\sum_{i \in\{\text { Lakes Unsatisfying E.S }\}}$ is actual COD Concentration in B.E $\times i^{\prime}$ S Capacity

\section{E.S: Environmental Standard, B.E: Base Year}

The base year is 2004, which is the base year for the sixth total volume control based on the Water Pollution Control Law. COD emissions in closed sea areas are published in [28].

The data on the COD concentration in lakes and marshes are published in [26, 27]. The data on the volume of lakes and marshes are extremely limited [29, 30, 31]. If the actual concentration in volume $X$ is summarized for natural lakes and marshes and man-made lakes and marshes with a storage volume of 10 million cubic meters or more, which have not achieved the environmental quality standard, the actual flow for lakes and marshes becomes $106,061.188 \mathrm{~kg}$.

The target flow is a sum of the target flow for the designated sea areas and the target flow for lakes and marshes, as shown in the following equation.

\section{COD Target Flow=}

Total Virtual Capacity of the Designated Closed Seas in B.E

$\times 1$ 'st Class COD Concentration of the Fishery Category $A$

$+\sum_{i \in\{\text { Lakes Unsatisfying E.S\} }} i$ 's COD Concentration of E.S $\times i$ 's Capacity

In each case, emissions will be obtained by multiplying the environmental quality standard (concentration) by the volume. A virtual volume will be used for the designated sea areas. The environmental quality standard value for the 
designated sea areas was set at $2 \mathrm{mg} / \mathrm{l}$ with the water use purpose of Category A, "Fishery class 1, water bath, natural environment conservation."

For the target flow for the designated sea areas, the emission reduction amount for 2009 was specified in the sixth total volume control. For designated sea areas, a value obtained by multiplying a virtual water amount in the designated sea area, which is obtained by dividing the actual flow $(\mathrm{kg})$ by the average COD concentration $(\mathrm{mg} / \mathrm{l})$, by the environmental quality standard value for the designated sea area, $2(\mathrm{mg} / \mathrm{l})$, will be specified as the target flow.

Thus, the target flow becomes $295,337,731$ (kg/year), that is sum of 1.47643 $\times 10^{14} \times 2.0(\mathrm{mg} / 1) \times 10^{-6}(\mathrm{~kg} /$ year $)$ for the closed sea areas and $52,731(\mathrm{~kg} /$ year $)$ for the lakes.

\subsection{Water quality in lakes and closed water areas in terms of Nitrogen (N)}

The achievement rate for the environmental quality standard of Nitrogen $(\mathrm{N})$ remains low. The Measurement Results of Water Quality in Public Waters for FY 2009 shows that the achievement rate of the environmental quality standard for the total $\mathrm{N}$ and the total $\mathrm{N}$ in lakes and marshes was $52.2 \%$ (increase by $2.2 \%$ from the preceding fiscal year). In the meantime, the achievement rate in sea areas was $81.5 \%$ (decrease by $3.4 \%$ from the preceding fiscal year) [19].

The actual flow of $\mathrm{N}$ is a sum of the COD emissions to the designated enclosed water areas (Tokyo Bay, Ise Bay, Seto Inland Sea) and N emissions to lakes and marshes. While the annual total emissions are published for the former, the $\mathrm{N}$ emissions for the latter will be estimated by multiplying the $\mathrm{N}$ concentration in lakes and marshes, where the environmental quality standard of $\mathrm{N}$ is not satisfied, by the volume of the lakes and marshes.

\section{$N$ Actual Flow $=$ \\ Tolal $N$ Emission of theDesignated Closed Seas of B.E + \\ $\sum_{i \in\{\text { Lakes Unsatisfying E.S }\}} i^{\prime}$ s actual N Concentration in B.E $\times i^{\prime}$ s Capacity}

\section{E.S: Environmental Standards, B.E: Base Year}

The base year is 2004, which is the base year for the sixth total volume control based on the Water Pollution Control Law.

The data on the $\mathrm{N}$ concentration in lakes and marshes are published in [26, 27]. The data on the volume of lakes and marshes are extremely limited. If the actual concentration in volume $\mathrm{X}$ is summarized for natural lakes and marshes and man-made lakes and marshes with a storage volume of 10 million cubic meters or more, which have not achieved the environmental quality standard, the actual flow for lakes and marshes becomes 11,311.16844 kg.

The target flow is a sum of the target flow for the designated sea areas and the target flow for lakes and marshes, as shown in the following equation. In each case, emissions will be obtained by multiplying the environmental quality standard (concentration) by the volume. A virtual volume will be used for the designated sea areas. 


\section{$N$ Target Flow $=$}

Tolal Virtual Capacity of the Designated Closed Seas in B.E $\times$

Standard N Concentration of the Category II in B.E +

$\sum_{i \in\{\text { Lakes Unsatisfying E.S }\}} i^{\prime}$ S Standard N Concentration $\times i^{\prime} s$ Capacity

The environmental quality standard value for the designated sea areas was set at $0.2 \mathrm{mg} / 1$ with the water use purpose of Category II "Fishery class 1, 2, 3; Fishery Type 1; water both."

For the target flow of the designated sea areas, the target emission reduction amount for 2009 was specified in the sixth total volume control.

For designated sea areas, a value obtained by multiplying a virtual water amount in the designated sea area, which is obtained by dividing the present flow $(\mathrm{kg})$ by the average concentration $(\mathrm{mg} / \mathrm{l})$, by the Class II environmental quality standard value for the designated sea area, $0.2(\mathrm{mg} / \mathrm{l})$, will be specified as the target flow.

Thus, the target flow becomes $178,450,334$ (kg/year), that is sum of 8.92219 x $10^{14}(1 /$ year $) \times 0.2(\mathrm{mg} / \mathrm{l}) \times 10^{-6}(\mathrm{~kg} /$ year $)$ for the closed sea areas and 6,595 $(\mathrm{kg} /$ year) for the lakes.

\subsection{Water quality in lakes and closed water areas in terms of total phosphorus (P)}

The present flow of total phosphorus $(\mathrm{P})$ is a sum of the total $\mathrm{P}$ emissions to the designated enclosed water area (Tokyo Bay, Ise Bay, Seto Inland Sea) and the total $\mathrm{P}$ emissions to lakes and marshes. While the annual total emissions are published for the former, the total $\mathrm{P}$ emissions will be estimated by multiplying the total $\mathrm{P}$ in lakes and marshes, where the environmental quality standard is not satisfied, by the volume of the lakes and marshes.

$$
\begin{aligned}
& \text { P Actual Flow }= \\
& \text { Total P Emission of the Designated Closed Seas in B.E+ } \\
& \sum_{i \in\{\text { Lakes Unsatisfying E.S\} }} i^{\prime} \text { S actual P Concentration in B.EXi's Capacity }
\end{aligned}
$$

The base year is 2004, which is the base year for the sixth total volume control based on the Water Pollution Control Law. The data on the total phosphorus (P) emissions in closed sea areas are published in [28]. The data on the total $P$ in lakes and marshes are published in $[26,27]$. The data on the volume of lakes and marshes are extremely limited. If the actual concentration in volume $\mathrm{X}$ is summarized for natural lakes and marshes and man-made lakes and marshes with a storage volume of 10 million cubic meters or more, which have not achieved the environmental quality standard, the actual flow for lakes and marshes becomes $248.272523 \mathrm{~kg}$.

From the above findings, the actual flow of total phosphorus (P) becomes $20,695,500+248.2725=20,695,748 \mathrm{~kg}$.

The target flow is a sum of the target flow for the designated sea areas and the target flow for lakes and marshes, as shown in the following equation. 
$P$ Target Flow $=$

Total Virtual Capacity of the Designated Closed Seas in B.E

$\times$ Standard P Concentration of the Category II in B.E

$+\sum_{i \in\{\text { Lakes Unsatisfying E.S }\}}$ is Standard P Concentration $\times$ is Capacity

In each case, emissions will be obtained by multiplying the environmental quality standard (concentration) by the volume. A virtual volume will be used for the designated sea areas.

The environmental quality standard value for the designated sea areas was set at $0.01 \mathrm{mg} / \mathrm{l}$ with the water use purpose of Category II "Fishery class 1, 2, 3; Fishery Type 1; water both."

For the target flow of the designated sea areas, the emission reduction amount for 2009 was specified in the sixth total volume control.

For designated sea areas, a value obtained by multiplying a virtual water amount in the designated sea area, which is obtained by dividing the present flow $(\mathrm{kg})$ by the average concentration $(\mathrm{mg} / \mathrm{l})$, by the Class II environmental quality standard value for the designated sea area, $0.01(\mathrm{mg} / \mathrm{l})$, will be specified as the target flow.

Thus, the target flow becomes $20,695,748(\mathrm{~kg} / \mathrm{year})$, that is sum of 6.290125 x $10^{14}(1 /$ year $) \times 0.2(\mathrm{mg} / \mathrm{l}) \times 10^{-6}(\mathrm{~kg} /$ year $)$ for the closed sea areas and 116 $(\mathrm{kg} /$ year) for the lakes.

\subsection{Waste management}

The Second Basic Plan for Promoting the Creation of a Recycling-Oriented Society [38] sets numerical targets for the material flow indices of resourceproductivity, recycling rate, and the final disposal amount of waste. The target year is 2015. In addition, as activity indices, steady enforcement of the following activities is set out:

(1) Reduction of waste volume;

(2) Change of consciousness/behaviour toward the creation of a recycling-based society;

(3) Promotion of recycling-based society business; and

(4) Individual recycling laws and plans, etc.

In the JEPIX2010, the final waste disposal amount will be calculated for the material flow indices and EcoFactors of wastes (household solid waste, waste from business sector).

\subsubsection{Waste (final disposal amount)}

As the latest actual flow data, the general waste final disposal amount [39] and the industrial waste final disposal amount [40] in 2007 are published. The total amount of the final disposal amount is $26,492,427,000 \mathrm{~kg}$

The Basic Plan for Promoting the Creation of a Recycling-Oriented Society (March 2008) sets out a target of reducing the final disposal amount to 23 million tons by fiscal year 2015 . 
The Second Basic Plan for Promoting the Creation of a Recycling-Oriented Society sets out the following numerical targets for the reduction of the household solid waste and the waste from business sector.

\subsubsection{Household solid waste}

The household solid waste, "the per-capita daily amount of household waste generated," which is defined as the amount excluding the group collection amount, recyclable waste, and so on, with the objective of evaluating the efforts of citizens in waste reduction and their cooperation for separate collection, will be reduced by approximately $20 \%$ from the fiscal year 2000 level.

For household waste, information is published by the respective prefectures. The target flow will be obtained by obtaining the daily per-capita target emissions, which is $20 \%$ less than the daily per-capita waste emissions in fiscal year 2000, and by multiplying it by the total population in 2008 . As a result, the actual flow is $34,103,587,710 \mathrm{~kg}$ and the target flow is $27,670,425,388 \mathrm{~kg}$

\subsubsection{Waste from business sector}

For waste from business sector, given the significant variety in the number of establishments and the significant difference observed in waste emissions according to the size of establishments, not the amount of waste per establishment but the "total amount" of waste from business sector will be reduced by approximately $20 \%$ from the fiscal year 2000 level.

Similar information as in household waste is also published for waste from business sector. Waste reduction by $20 \%$ from the daily per-capita emissions in 2008 is set out as the target similarly as in household solid waste. As a result, the actual flow is $1,920,000,000 \mathrm{~kg} \mathrm{~kg}$ and the target flow is $27,620,610,202 \mathrm{~kg}$

\section{Conclusion}

In JEPIX 2010, there are diversified identified categories of environmental aspect, including GHG, ODS, SOX, NOX, particles/dust, dioxins, VOC, total Nitrogen, total Phosphorous, COD, BOD, waste material. Comparison of the two sets of EcoFactors (JEPIX 2003 and JEPIX 2010) and Japanese national ecobalances, which are obtained from the EcoFactors, show the change of priority of Japanese environmental policy.

Since the development of JEPIX 2003, environmental regulation as well as available inventory data has changed. Responding to those changes and needs of industry, JEPIX 2010 has been developed using the most resent Japanese inventory data and legislation target.

\section{Acknowledgement}

This work was supported by JSPS KAKENHI Grant Number 23530591. 


\section{References}

[1] Bare, C., GLORIA, T., Critical Analysis of the Mathematical Relationships and Comprehensiveness of Life Cycle Impact Assessment Approaches, Environmental Science and Technology, 40(4), pp. 1104-1113, 2006.

[2] Itsubo, N., Sakagami, M., Washida, T., Kokubu, K., Inaba, A., Weighting across safeguard subjects for LCIA through the application of conjoint analysis, Int. J. LCA, 9(3), pp. 196-205, 2004.

[3] Ahbe, S., Braunschweig, A, Müller-Wenk, R., Method for ecobalancing based on ecological optimization, BRWAL 133, 1990.

[4] Ministry of the Environment, Toward a sustainable society - Environmental Reporting - Guidelines (2007 Edition), June 2007.

[5] Kokubu, K., Nisioka, E., Hirayama, K., An Analysis of Environmental Reporting and Accounting in Japan, $5^{\text {th }}$ International Ecobalance Conference, P585-586, 2002.

[6] Siegenthaler, C., Kumagai, S., Shinozuka, E., Development of Ecoscarcity Japaneses Version, $5^{\text {th }}$ International Ecobalance Conference, pp. 581-582, 2002.

[7] Miyazaki, N., Siegenthaler, C., Kumagai, S., Shinozuka, E. and Nagayama, A., Japan Environmental Policy Index Method for EcoRating and Environmental Accounting based on the EcoScarcity Principle, Report of Japan Science and Technology Corporation, 2003.

[8] Miyazaki N., Siegenthaler C., Schoenbaum T. and Azuma K., Japan Environmental Policy Priorities Index (JEPIX) - Calculation of EcoFactors for Japan: Method for Environmental Accounting based on the EcoScarcity Principle, International Christian University Social Science Research Institute, Monograph Series No. 7, Tokyo, 2004.

[9] Miyazaki, N., Uozumi, R., Yamatake Corporation, Report on JEPIX forum activities, Social Science Research Institute Monograph Series 15, 2008.

[10] NIES, National Greenhouse Gas Inventory Report of JAPAN, wwwgio.nies.go.jp/aboutghg/nir/nir-j.html

[11] Global Warming Prevention Headquarters, 28 March 2008, Kyoto Protocol Target Achievement Plan.

[12] Ministry of the Environment, Annual report on the results of monitoring of the ozone layer, etc., FY2009, 2010.

[13] National Institute of Technology and Evaluation, Details on the estimation method, etc. of emissions non-notified to PRTR, 2009, www.prtr.nite.go.jp/prtr/det_est21.html

[14] Bureau of Statistics, Ministry of Internal Affairs and Communications, World Statistics, 2011, www.stat.go.jp/data/sekai/index.htm

[15] Ministry of Internal Affairs and Communications, Emission targets for stationary sources, www.soumu.go.jp/main sosiki/hyouka/seisakunaiyo/ pdf/041122_1_s6.pdf

[16] Ministry of the Environment, Summary of Comprehensive Survey on Air Pollutant Emissions (2005), www.env.go.jp/press/file_view.php? serial $=11263 \&$ hou $\_$id $=9621$ 
[17] Automobile Inspection and Registration Association, Statistics of automobile fleet, www.airia.or.jp/number/index.html

[18] Ministry of the Environment, Research and study of automobile exhaust gas emissions per unit and calculated the total amount (FY2004).

[19] Ministry of the Environment: On the Result of the water quality measurement in public water area, 26 November 2010, www.env.go.jp/press/press.php?serial=13171.

[20] Japan Sewage Works Association, Study guide and commentary Sewerage another watershed comprehensive plan, September, 2008.

[21] JSA, www.jsa02.or.jp/01jyokaso/01_1a.html

[22] Japan Livestock Industry Association, Environmental preservation guidance manual, 2001, 2008.

[23] Ministry of Agriculture, Forestry and Fisheries of Japan, Livestock Statistics 2009, www.maff.go.jp/j/tokei/teikyou data/seisan/tikusan 10/index.html

[24] Environmental management Bureau, Ministry of the Environment, November 2010, Measurements of water quality for public water 2008.

[25] Itsubo, N., Development of Impact Assessment Methodology for Manufacturing Materials, Thesis for a doctorate in University of Tokyo, 1997.

[26] Environmental management bureau, Ministry of the Environment, November 2010, Measurements of water quality for public water 2008.

[27] Environmental management bureau, Ministry of the Environment, November 2005, Measurements of water quality for public water 2004.

[28] Ministry of the Environment, Press Release, For formulating chemical oxygen demand, total reduction of the basic policies pertaining to the nitrogen content and phosphorus content, 20 ${ }^{\text {th }}$ November 2006.

[29] Ministry of the Environment, Lake survey report third basic research $\left(4^{\text {th }}\right.$ national edition), 1993.

[30] Ministry of the Environment, Lake survey report third basic research (national edition), 1987.

[31] Ministry of the Environment, Research report related inland waters on the National Environmental Research $2^{\mathrm{Nd}}$ Edition nationwide (lakes), 1980.

[32] Ministry of the Environment, November 2009, Inventory of dioxin emissions (emission inventory).

[33] Ministry of the Environment, VOC emissions inventory, www.env.go.jp/air/osen/voc/inventory.html

[34] Ministry of the Environment, Reporting results of monitoring stations measuring ambient air, in automobile exhaust gas monitoring stations, www.env.go.jp/press/press.php?serial=13527, 28 February 2011.

[35] Dockery, D.W., Pope, C.A.: Acute respiratory effects of particular air pollution, Annual Review of Public health 15: p.102-137,1994.

[36] Kannnari,A., Tonooka, Y., Baba, T. and Murano, K.: Development of Multiple-species $1 \mathrm{~km} \mathrm{x} 1 \mathrm{~km}$ Resolution Hourly Basis Emissions Inventory for Japan, Aromos. Env., 41,pp. 3428-3429, 2007. 
52 Environmental Impact

[37] Nati0nal Institute for Environmental Studies, Numerical database environment, www.nies.go.jp/igreen/td_down.html

[38] The fundamental plan for Establishing a Sound Material-Cycle Society, March 2008.

[39] Ministry of the Environment、Technical Information of Industrial Waste, www.env.go.jp/recycle/waste tech/ippan/h19/index.html, 2007.

[40] Division of industrial waste, Waste management and recycling department, 14 January 2010, Minister's secretariat, Ministry of the Environment, Situation such as emissions and processing of industrial waste (FY2007). 